\title{
Combined effect of asbestos and smoking on mortality from lung cancer and mesothelioma in factory workers
}

\author{
G BERRY,' M L NEWHOUSE, ${ }^{2}$ AND P ANTONIS ${ }^{2}$
}

From the Commonwealth Institute of Health, ' University of Sydney, New South Wales 2006, Australia, and the TUC Centenary Institute of Occupational Health, ${ }^{2}$ London School of Hygiene and Tropical Medicine, London WC1E 7HT, UK

ABSTRACT The mortality of over 1250 male and 420 female asbestos factory workers was observed over the period 1971-80. Smoking habits were obtained from the subjects in 1971 before the start of the follow up period. Mortality due to lung cancer and to mesothelioma was related to smoking habits. After allowing for the effect of smoking on lung cancer the relative risk due to asbestos was highest for those who had never smoked, lowest for current smokers, and intermediate for ex-smokers; the trend was statistically significant $(p<0.05)$. There was no significant association between smoking and deaths due to mesothelioma. Data from several studies are reviewed, and although overall non-smokers have a relative risk of lung cancer due to asbestos that is 1.8 times that of smokers, there is some uncertainty on the accuracy of this figure because of possible biases and sampling variation. Overall the evidence is that mesothelioma risk is independent of smoking.

In an earlier paper we examined the interrelationship between smoking and exposure to asbestos in the aetiology of lung cancer, using data from a mortality study of men and women employed at some time in an asbestos factory in the east end of London.' ${ }^{\prime}$ Our study, which was stimulated by the classic paper of Selikoff $e t a l,{ }^{2}$ was preliminary in that it combined smoking data obtained to set up a prospective study with retrospective smoking data on those who had died in the previous 10 years.

In the present paper the results of almost 10 years' follow up in the prospective study are presented. Also smoking habits obtained retrospectively for those dying during the follow up are compared with those obtained during life to see if our earlier approach of combining prospective and retrospective smoking information was valid.

Other published studies that enable the combined effects of smoking and exposure to asbestos on lung cancer to be analysed are reviewed and a combined assessment is presented.

Received 21 November 1983

Accepted 19 December 1983

\section{Population studied}

The population studied consisted of men born between 1900 and 1930 who were first employed at the factory between 1 April 1933 and 31 December 1955 and who had not been employed as laggers, and women first employed at the factory between 1936 and 1942. There were 1543 men and 538 women who were traced as alive on 1 July 1971 . Those men and women whose smoking habits were established by questionnaire or interview in 1971 were included in the present analysis. The number included and their smoking habits are shown in table 1. These numbers differ from those reported in our earlier paper ${ }^{\prime}$ since some questionnaires were returned late, and some people previously included in the study with unknown smoking habits had either died or emigrated before receiving the smoking questionnaire. Smoking habits were obtained from $81 \%$ of those still alive and traced in 1971 .

\section{Methods}

The period of study was from 1 July 1971 to 31 December 1980 for the men and to 30 June 1980 
Table 1 Smoking habits as reported in 1971

\begin{tabular}{lcl}
\hline Smoking habit & Men & Women \\
\hline Never smoked & $74(5.9 \%)$ & $118(27.9 \%)$ \\
Ex-smokers & $246(19.6 \%)$ & $96(22.7 \%)$ \\
Smokers & $933(74.5 \%)$ & $209(49.4 \%)$ \\
Total & $1253(100.0 \%)$ & $423(100.0 \%)$ \\
\hline
\end{tabular}

for the women. Details of deaths occurring in this period were obtained from the Office of Population Censuses and Surveys. Information on cause of death was supplemented by studies of postmortem reports and histological material; deaths classified as due to mesothelioma in this paper were either confirmed or identified by examination of the histology.

For subjects dying within the study period, particularly those dying in hospital, attempts were made to obtain the smoking habits retrospectively from hospital records or general practitioners.

The subjects were classified according to category of exposure to asbestos, light/moderate or severe, and to duration of exposure, less or longer than two years.

The aim of the analysis of deaths due to lung cancer was to estimate the effect of asbestos exposure and to assess if the asbestos effect was dependent on smoking habits. In order to obtain unbiased estimates of the asbestos effects it is necessary to make allowance for other factors known to be associated with lung cancer mortality; factors considered were sex, age, period, region, and smoking habits. Since there was no control group of workers unexposed to asbestos in our study the asbestos effect was considered relative to the general population of the region in which the factory was situated. The first step was to calculate the expected numbers of deaths due to lung cancer based on the sex-, age-, and period-specific death rates for England and Wales using the subject-years method. ${ }^{3}$ These expected numbers were multiplied by the standardised mortality ratio (SMR) for lung cancer for the Greater London area (table 2). Allowance for smoking habits was made by multiplying the expected numbers by a different factor for each smoking group. These factors represented the relative effects of different smoking habits on lung cancer mortality,

Table 2 Adjustments of expected numbers of lung cancer

\begin{tabular}{lcc}
\hline & Men & Women \\
\hline SMR Greater London 1972-9 & 113 & 128 \\
Smoking habit ${ }^{*}:$ & 0.10 & 0.27 \\
Never smoked & 0.44 & 0.88 \\
Ex-smokers & 1.34 & 1.90 \\
\hline Smokers & \\
\hline
\end{tabular}

*Factors to adjust expected lung cancer deaths based on national rates to take account of smoking habits. and were calculated using the results of Doll and colleagues on mortality from lung cancer according to smoking habits of British doctors, ${ }^{45}$ combined with information on the distribution of smoking habits in the national population..$^{6}$ Account was also taken of the proportion of men in the study who smoked a pipe or cigars since this proportion differed from that of the British doctors. The factors are given in table 2 . Within each group the excess lung cancer rate is expressed as the ratio of observed to expected deaths due to lung cancer. These rates estimate the relative risk due to asbestos exposure, after allowing for smoking.

A review of results from similar studies was undertaken. Within each study the effect of smoking on the asbestos effect is expressed as the ratio of the relative risk due to asbestos exposure in nonsmokers to that in smokers; this is termed the relative asbestos effect (NS:S). If the asbestos effect was the same for non-smokers as for smokers then the relative asbestos effect would be equal to 1 , whereas a value greater than 1 indicates that the effect of asbestos is greater in non-smokers than in smokers, and vice versa.

The effects of sex, category, duration of exposure to asbestos, and smoking on the relative risk of lung cancer due to asbestos were fitted simultaneously using log-linear regression models. ${ }^{7}$ Since mesothelioma is a rare cause of death in the general population, deaths due to this cause were analysed in terms of the rate per 100000 subject-years at risk; these rates were also analysed using log-linear regression models. Computations were carried out using GLIM. ${ }^{8}$

\section{Results}

\section{COMPARISON OF SMOKING HABITS OBTAINED}

DURING LIFE AND AFTER DEATH

Smoking habits were obtained after death for 114 men and women whose smoking habits had been determined directly during 1971 . The comparison is shown in table 3; retrospectively it was not always possible to discriminate ex-smokers from smokers and such cases were labelled "smoked at some time." Some of those who were ex-smokers in 1971 had started smoking again before their death, while some of those who were smokers in 1971 gave up before their death. Of the 12 who reported in 1971 that they had never smoked, eight were similarly recorded at death, two were recorded as ex-smokers (one for over 20 years), and another two as smokers at death. Of the 11 recorded as never smoked at death, eight had claimed in 1971 to have never smoked, two had stated that they were ex-smokers, and another was a smoker in 1971. Thus there are 
Table 3 Comparison of smoking habits obtained during life and after death

\begin{tabular}{lllllr}
\hline $\begin{array}{l}\text { Smoking habits obtained during life } \\
\text { in 1971 }\end{array}$ & No & \multicolumn{3}{l}{ Smoking habits obtained at death } \\
\cline { 3 - 6 } & & Never smoked & Ex-smoker & Smoked & Smoked at some time \\
\hline Never smoked & 12 & 8 & 2 & 2 & 0 \\
Ex-smoker & 26 & 2 & 15 & 2 & 7 \\
Smoker & 76 & 1 & 12 & 33 & 30 \\
\hline
\end{tabular}

discrepancies between the two methods of determining smoking status and whereas smoking habits were validated for most smokers, where "never smoked" is recorded, either during life or at death, the validation rate is lower than for those who had smoked.

\section{REVISION OF EARLIER RESULTS}

In an earlier paper the observed number of deaths from lung cancer was adjusted to take account of the finding that smoking habits were more likely to be available if lung cancer was the cause of death.' Though this adjustment was valid it had the disadvantage of producing fractional observed numbers and a method of allowing for the bias by adjusting the expected numbers has now been found. Table 4 shows the revised results. The conclusions remain the same with the ratio of observed to expected being similar in women for those who had never smoked and those who had smoked, and with too few men who had never smoked to make the comparison.

\section{PROSPECTIVE RESULTS}

The observed and expected deaths due to lung cancer (excluding mesotheliomas) during the follow up period 1971-80 are shown in table 5 together with the number of deaths due to mesotheliomas of both pleural and peritoneal origin.

The results for lung cancer are summarised in table 6 with the excess lung cancer rates due to asbestos expressed as the ratio of observed to expected. In the final column of table 6 the relative risks due to asbestos exposure are given after combining the data for men and women, and standardis- ing each smoking group for sex and degree of exposure. For men the excess was highest for those who had never smoked, lowest for those who were smoking in 1971, and the ex-smokers were intermediate. This trend was statistically significant $(\mathrm{p}<$ 0.05 ) as was the difference between ex-smokers and smokers. For women, the never smoked had the highest excess and the ex-smoker and smokers had similar rates. The difference between the never smoked and those who had smoked at some time was not significant. Combining men and women gave a significant trend $(p<0.05)$ similar to that seen in men but neither the difference between the never smoked and those who had smoked at some time nor that between ex-smokers and smokers was significant.

The mesothelioma results are summarised in table 7. For men, ex-smokers had the highest mesothelioma rate, and this was significantly $(\mathrm{p}<8$ $0.05)$ higher than for the smokers. There were no mesotheliomas in the men who had never smokedo but this was not a significant finding because of the low number of subject-years at risk. For women, the never smoked had the highest rate but the differences between the three smoking groups were not significant. Combining men and women and adjusting for sex and asbestos exposure there were no significant differences between the smoking groups.

\section{Discussion}

In a review of published studies in 1977 Saracci concluded that the most plausible explanation of the data was that the effects of asbestos and smoking

Table 4 Comparison of observed and expected cancers of lung for those with severe exposure to asbestos during 1960-70 (revised figures of 1972 paper')

\begin{tabular}{|c|c|c|c|c|}
\hline \multirow[t]{2}{*}{ Smoking habits } & \multirow[t]{2}{*}{ Observed* } & \multirow[t]{2}{*}{ Expected $†$} & \multicolumn{2}{|c|}{ Obs/exp with mesotheliomas } \\
\hline & & & Included & Excluded \\
\hline $\begin{array}{l}\text { Men: } \\
\text { Never smoked } \\
\text { Ex-smokers } \\
\text { Smokers }\end{array}$ & $\begin{array}{r}0 \\
2 \\
32(5)\end{array}$ & $\begin{array}{r}0 \cdot 0 \\
0 \cdot 3 \\
12 \cdot 0\end{array}$ & $\begin{array}{r}- \\
6 \cdot 7 \\
2 \cdot 7\end{array}$ & $\begin{array}{l}\overline{6 \cdot 7} \\
2 \cdot 2\end{array}$ \\
\hline $\begin{array}{l}\text { Women: } \\
\text { Never smoked } \\
\text { Smoked at some time }\end{array}$ & $\begin{array}{r}2(1) \\
18(4)\end{array}$ & $\begin{array}{l}0.2 \\
1.9\end{array}$ & $\begin{array}{r}10.0 \\
9.5\end{array}$ & $\begin{array}{l}5 \cdot 0 \\
7 \cdot 4\end{array}$ \\
\hline
\end{tabular}

*Figures in parentheses are pleural mesotheliomas included in the observed cancers of lung (ICD 162-3).

†After allowing for the effect of smoking. 
Table 5 Observed and expected deaths from cancer of the lung and mesothelioma during 1971-80

\begin{tabular}{|c|c|c|c|c|c|c|}
\hline \multirow[t]{2}{*}{ Smoking habits in 1971} & \multirow[t]{2}{*}{ No of subjects } & \multirow[t]{2}{*}{ Subject-years at risk } & \multirow[t]{2}{*}{ Total deaths } & \multicolumn{2}{|c|}{ Lung cancer deaths } & \multirow{2}{*}{$\begin{array}{l}\text { Mesothelioma } \\
\text { deaths (pl, perit) } \dagger\end{array}$} \\
\hline & & & & observed & expected ${ }^{*}$ & \\
\hline \multicolumn{7}{|c|}{ Men } \\
\hline \multicolumn{7}{|l|}{$\begin{array}{l}\text { Low/moderate asbestos } \\
\text { exposure: }\end{array}$} \\
\hline $\begin{array}{l}\text { Never smoked } \\
\text { Ex-smokers } \\
\text { Smokers }\end{array}$ & $\begin{array}{r}45 \\
123 \\
411\end{array}$ & $\begin{array}{r}396 \\
1092 \\
3557\end{array}$ & $\begin{array}{r}6 \\
18 \\
84\end{array}$ & $\begin{array}{r}1 \\
3 \\
17\end{array}$ & $\begin{array}{r}0.10 \\
1.07 \\
11.29\end{array}$ & $\begin{array}{l}0 \\
4 \\
3\end{array}(3,1)$ \\
\hline \multicolumn{7}{|c|}{ Severe asbestos } \\
\hline $\begin{array}{l}\text { exposure: } \\
\text { Never smoked } \\
\text { Ex-smokers } \\
\text { Smokers }\end{array}$ & $\begin{array}{r}29 \\
123 \\
522\end{array}$ & $\begin{array}{r}273 \\
1003 \\
4394\end{array}$ & $\begin{array}{r}2 \\
38 \\
135\end{array}$ & $\begin{array}{r}0 \\
8 \\
35\end{array}$ & $\begin{array}{r}0.06 \\
1.25 \\
14.63\end{array}$ & 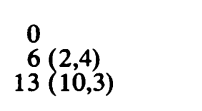 \\
\hline \multicolumn{7}{|c|}{ Women } \\
\hline \multicolumn{7}{|l|}{$\begin{array}{l}\text { Low/moderate asbestos } \\
\text { exposure: }\end{array}$} \\
\hline $\begin{array}{l}\text { Never smoked } \\
\text { Ex-smokers } \\
\text { Smokers }\end{array}$ & $\begin{array}{l}17 \\
12 \\
27\end{array}$ & $\begin{array}{r}128 \\
93 \\
220\end{array}$ & $\begin{array}{l}5 \\
3 \\
4\end{array}$ & $\begin{array}{l}\mathbf{0} \\
\mathbf{0} \\
\mathbf{0}\end{array}$ & $\begin{array}{l}0.04 \\
0.09 \\
0.32\end{array}$ & $\begin{array}{l}1(1,0) \\
0 \\
0\end{array}$ \\
\hline $\begin{array}{l}\text { Severe asbestos } \\
\text { exposure: }\end{array}$ & & & & & & \\
\hline $\begin{array}{l}\text { Never smoked } \\
\text { Ex-smokers } \\
\text { Smokers }\end{array}$ & $\begin{array}{r}101 \\
84 \\
182\end{array}$ & $\begin{array}{r}799 \\
659 \\
1413\end{array}$ & $\begin{array}{l}26 \\
24 \\
52\end{array}$ & $\begin{array}{r}3 \\
2 \\
10\end{array}$ & $\begin{array}{l}0.20 \\
0.50 \\
2.02\end{array}$ & $\begin{array}{l}4(1,3) \\
2(1,1) \\
4(3,1)\end{array}$ \\
\hline
\end{tabular}

*Calculated after making allowance for the effect of smoking, sex, age, period, and region.

+ Numbers in parentheses are the numbers of mesotheliomas of pleural and peritoneal origin respectively.

Table 6 Excess lung cancer due to exposure to asbestos during 1971-80

\begin{tabular}{|c|c|c|c|c|c|c|c|}
\hline \multirow{2}{*}{$\begin{array}{l}\text { Smoking habits } \\
\text { in } 1971\end{array}$} & \multicolumn{3}{|l|}{ Men } & \multicolumn{3}{|c|}{ Women } & \multirow{2}{*}{$\begin{array}{l}\text { Combined excess } \\
\text { ratio* }\end{array}$} \\
\hline & Obs & $\operatorname{Exp}$ & Ratio & Obs & $\operatorname{Exp}$ & Ratio & \\
\hline $\begin{array}{l}\text { Never smoked } \\
\text { Ex-smokers } \\
\text { Smokers }\end{array}$ & $\begin{array}{r}1 \\
11 \\
52\end{array}$ & $\begin{array}{r}0.16 \\
2 \cdot 32 \\
25 \cdot 92\end{array}$ & $\begin{array}{l}6 \cdot 2 \\
4 \cdot 7 \\
2 \cdot 0\end{array}$ & $\begin{array}{r}3 \\
2 \\
10\end{array}$ & $\begin{array}{l}0 \cdot 24 \\
0 \cdot 59 \\
2 \cdot 34\end{array}$ & $\begin{array}{r}12 \cdot 5 \\
3 \cdot 4 \\
4 \cdot 3\end{array}$ & $\begin{array}{l}7 \cdot 3 \\
4 \cdot 0 \\
2 \cdot 2\end{array}$ \\
\hline
\end{tabular}

* Combining men and women and standardising for sex and category and duration of exposure.

Table 7 Mesothelioma death rates per 100000 subject-years during 1971-80

\begin{tabular}{|c|c|c|c|c|c|c|c|c|c|c|}
\hline \multirow{2}{*}{$\begin{array}{l}\text { Smoking habits } \\
\text { in } 1971\end{array}$} & \multicolumn{3}{|l|}{ Men } & \multicolumn{3}{|c|}{ Women } & \multicolumn{3}{|c|}{ Total } & \multirow{2}{*}{$\begin{array}{l}\text { Combined } \\
\text { ratet }\end{array}$} \\
\hline & No & $s y^{*}$ & Rate & No & sy & Rate & No & sy & Rate & \\
\hline $\begin{array}{l}\text { Never smoked } \\
\text { Ex-smokers } \\
\text { Smokers }\end{array}$ & $\begin{array}{r}0 \\
10 \\
16\end{array}$ & $\begin{array}{r}669 \\
2095 \\
7951\end{array}$ & $\begin{array}{r}0 \\
477 \\
201\end{array}$ & $\begin{array}{l}5 \\
2 \\
4\end{array}$ & $\begin{array}{r}927 \\
752 \\
1633\end{array}$ & $\begin{array}{l}539 \\
266 \\
245\end{array}$ & $\begin{array}{r}5 \\
12 \\
20\end{array}$ & $\begin{array}{l}1596 \\
2847 \\
9584\end{array}$ & $\begin{array}{l}313 \\
421 \\
209\end{array}$ & $\begin{array}{l}299 \\
416 \\
213\end{array}$ \\
\hline
\end{tabular}

* Subject-years at risk.

†Combining men and women and standardising for sex and category and duration of exposure.

combine multiplicatively to produce lung cancer'; that is, that after taking account of smoking habits in the calculation of expected deaths from lung cancer the relative risk due to asbestos is the same for smokers as for non-smokers.

Our results (table 6) are superficially inconsistent with Saracci's conclusion since the excess ratio showed a significant trend, with those who had never smoked having the highest relative excess. Nevertheless, a non-negligible proportion of those reporting in 1971 that they had never smoked may have smoked at some time according to information collected at death (table 3 ) and the pollution of the "never-smoked" group by a small proportion of smokers could be the explanation of the trend. Smoking information was obtained retrospectively for two of the four deaths from lung cancer in never smokers, and these two were also recorded as never smokers at death.

Since the review of Saracci ${ }^{9}$ more recent data have been published for several studies and the results of the main prospective studies are summarised in table 8. For each study the relative asbestos effect has been calculated as the ratio of the asbestos effect in non-smokers to that in smokers. Approximate confidence intervals were calculated and the studies 
Table 8 Lung cancer and smoking in studies of asbestos workers

\begin{tabular}{|c|c|c|c|c|c|c|c|c|}
\hline \multirow[t]{2}{*}{ Study } & \multicolumn{3}{|c|}{ Non-smokers } & \multicolumn{3}{|c|}{ Smokers* } & \multirow{2}{*}{$\begin{array}{l}\text { Relative } \\
\text { asbestos effect } \\
\text { (NS:S) }\end{array}$} & \multirow{2}{*}{$\begin{array}{l}95 \% \text { Confidence } \\
\text { limits }\end{array}$} \\
\hline & Obs & $\operatorname{Exp}$ & Relative risk & Obs & $\operatorname{Exp}$ & Relative risk & & \\
\hline \multirow{7}{*}{ 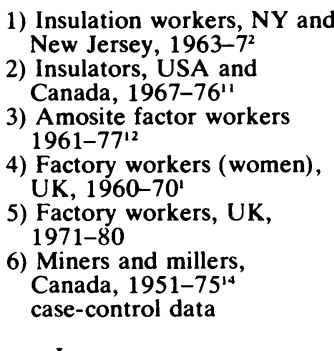 } & ${ }^{d} 0$ & 0.05 & 0 & 24 & $2 \cdot 98$ & $8 \cdot 1$ & 0 & $0-5 \cdot 0$ \\
\hline & 4 & 0.7 & $5 \cdot 7$ & 268 & $51 \cdot 0$ & $5 \cdot 3$ & $1 \cdot 1$ & $0 \cdot 3-2 \cdot 6$ \\
\hline & 5 & 0.2 & $25 \cdot 0$ & 45 & $9 \cdot 6$ & $4 \cdot 7$ & $5 \cdot 3$ & $1 \cdot 8-12 \cdot 2$ \\
\hline & 1 & $0 \cdot 2$ & $5 \cdot 0$ & 14 & $1 \cdot 9$ & $7 \cdot 4$ & $0 \cdot 7$ & $0 \cdot 1-3 \cdot 4$ \\
\hline & 4 & 0.55 & $7 \cdot 3$ & 75 & $31 \cdot 02$ & $2 \cdot 4$ & $3 \cdot 0$ & $0 \cdot 8-7 \cdot 5$ \\
\hline & Asbe & xposure & & & & & & \\
\hline & Yes & Not & & Yes & No $†$ & & & \\
\hline $\begin{array}{l}\text { Lung cancer } \\
\text { Controls }\end{array}$ & 17 & $\begin{array}{r}6 \\
103\end{array}$ & & 131 & 69 & & & \\
\hline $\begin{array}{l}\text { Controls } \\
\text { Combined studies }\end{array}$ & 98 & 103 & ${ }^{3 \cdot 0}$ & 274 & 240 & $1 \cdot 7$ & $\begin{array}{l}1.8 \\
1.8\end{array}$ & $\begin{array}{l}0 \cdot 7-5 \cdot 4 \\
1 \cdot 1-2 \cdot 8\end{array}$ \\
\hline
\end{tabular}

*Including ex-smokers; for studies 1-3 those who smoked only pipe or cigars or both are excluded.

†Lowest exposed group (see text).

were combined, taking account of the different effects due to asbestos in the different studies, using likelihood methods.?

The first study is of 370 insulation workers in New York and New Jersey, ${ }^{2}$ whose smoking habits were determined before the start of a four year follow up period. The expected figures quoted were calculated using data on the relation between lung cancer mortality and smoking from a study of the American Cancer Society. There were no deaths due to lung cancer in the non-smokers but the expectation was very low. Hence the relative asbestos effect had wide confidence limits, and the data are consistent with equal effects in smokers and non-smokers. Later results from this study have been published ${ }^{10}$ but are not considered here since the mortality after 1967 is included in a larger study ${ }^{11}$ considered below.

The second study is of insulators in the USA and Canada. "It was based on the mortality in a 10 year period of over 12000 workers, of whom $68 \%$ gave information on their smoking habits before the follow up started. Data for men not exposed to asbestos are taken from the study of the American Cancer Society. The expected figures given in the paper were based on non-smoking controls but standardised death rates were given for the different groups. In table 8 the expected number of deaths for smoking insulators was obtained by adjusting the expected number, based on non-smoking control rates, by the ratio of the standardised rates in controls. The asbestos effect was similar, between five and six fold, in non-smokers and smokers, but the confidence interval was wide because there were only four deaths due to lung cancer in non-smokers.

The third study is of 582 amosite asbestos factory workers. ${ }^{12}$ Smoking histories were obtained for over $97 \%$ before following up the group for mortality. Expected death rates were again obtained from the study of the American Cancer Society. Based on five deaths from lung cancer in non-smokers the excess rate due to asbestos in this group was 25 -fold; the excess for smokers was $4 \cdot 7$. Thus the relative asbestos effect was over 5 , and this was significantly different from equal effects in the two smoking groups. The figures given in table 8 were based on death certificate information. The causes of death on the death certificates were checked using hospital records and pathological material to give revised observed numbers of deaths due to lung cancer of three and 55 for non-smokers and smokers respectively. Using these revised figures the estimate at the relative asbestos effect was reduced to $2.6(95 \%$ confidence interval $0 \cdot 6$ to $7 \cdot 1$ ).

The fourth and fifth studies are from the asbestos factory workers reported on in this paper with figures extracted from tables 4 and 6 (using the adjusted figures of table 6). In the earlier study the asbestos effect was similar for non-smokers and smokers, although the confidence interval for the relative effect is wide. In the more recent study the non-smokers had a higher relative risk due to asbestos than smokers, although the difference was not quite significant after combining ex-smokers with smokers.

The sixth study is of chrysotile miners and millers in Quebec, ${ }^{13}$ using the most recent results on smoking. ${ }^{14}$ There was no unexposed group in this study but men were classified according to amount of exposure and, for the purpose of this summary, the lower exposure group was treated as a control group. The data on smoking and asbestos exposure 
were from a case-control study within the main prospective study. Asbestos exposure was established for all the deaths from lung cancer and for three controls for each case. Smoking habits were obtained directly from over $99 \%$ of those alive in 1970 and from relatives and friends for $93 \%$ of those who had died up to 20 years earlier. As observed by the authors, ${ }^{13}{ }^{14}$ the relative risk of lung cancer due to asbestos was greater for non-smokers than for smokers; the estimate of the relative asbestos effect was 1.8 but was not significantly greater than unity.

When the evidence from all six studies was combined there was little evidence of heterogeneity of the relative asbestos effect. The combined estimate was that the relative risk of lung cancer due to asbestos was $\mathbf{1 . 8}$ times greater in non-smokers than in smokers, and the $95 \%$ confidence interval was $1 \cdot 1$ to $2 \cdot 8$. There are several reasons why it may be invalid to accept this estimate at face value. Firstly, the confidence intervals were calculated on the assumption that expected deaths were known without error. This is the usual procedure with this method and is reasonable when expected death rates are based on a large number of deaths in a national population. In allowing for smoking in the calculation of death rates, however, the death rates were based on small numbers, particularly for non-smokers, and the sampling variation would not be negligible. As a result, the confidence intervals of table 8 will be too narrow. Secondly, there could be a bias in using data on the relative risk due to smoking obtained from one group in order to standarise another group. The relative risk could differ between our factory workers and Doll's doctors because of a different distribution of smoking patterns-for example, inhaling or duration of time smoked-between the two groups. It would have been preferable to work entirely within the set of factory workers, as Liddell et al did in their study, ${ }^{14}$ but this would have been too inaccurate in our study because there were only four deaths from lung cancer in non-smokers. The problem is less in the American studies because some of the investigators in the studies reported were also concerned in the study of the American Cancer Society and were able to select a control group matched for education and type of occupation." Thirdly, the classification of subjects into "non-smokers" and "smokers" may not be without error (table 3). Contamination of a group of nonsmokers by smokers would greatly increase the lung cancer risk of the group. For example, if $5 \%$ of those classified as non-smokers were ex-smokers and 5\% current smokers then the risk would be almost doubled. This amount of contamination could occur if about $2 \%$ of ex-smokers and $1 \%$ of current smokers were recorded as never-smoked. Such contamination would only cause a bias if the degree differed between the asbestos group and the controls. Fourthly, as shown in the study of amosite workers, ${ }^{12}$ misdiagnosis on the death certificate can result in bias between the two smoking groups. This study was the only one to provide significant evidence that the asbestos effect was different for non-smokers than for smokers but, after allowing for the differential misdiagnosis, the difference was no longer significant.

In view of the considerations of the previous paragraph we would not claim that it is established that non-smokers have a higher relative risk due to asbestos than smokers, although overall the data suggest that this may be the case.

The interpretation of the results on deaths from mesothelioma is simpler because the rarity of this tumour in people not exposed to asbestos means that it is not nessary to use data from a non-asbestos exposed control group. Those who had never smoked had a higher rate of mesothelioma than smokers (combining ex- and current smokers) but the relative effect was only 1.2 and not significant. Selikoff $e t$ al gave results for the amosite factory workers and the large group of insulators from USA and Canada. ${ }^{12}$ In both studies the men who had never smoked had the higher rate; the relative effect was 1.6 for the amosite workers based on three and nine mesotheliomas in non-smokers and smokers respectively, and in the insulators the relative effect was 1.1 based on 15 mesotheliomas in non-smokers and 105 in smokers. Neither difference was significant, and the three studies together provide insufficient evidence to contradict the view of McDonald and McDonald that it "seems improbable that tobacco smoking is an etiological factor of any importance in this disease." 15

Despite the uncertainty as to whether the relative risk for lung cancer due to asbestos is greater for non-smokers than for smokers, or whether the relative risks are equal, in absolute terms the smokers have the higher risk of dying of lung cancer as a result of their extra risk due to asbestos exposure. This is because their base risk is much higher due to smoking. ${ }^{16}$ The risk of mesothelioma appears independent of smoking. Therefore combining these two cancers, which are the two most important causes of excess deaths in asbestos workers, the smokers have the higher risk. People working with asbestos have even more to gain by giving up smoking than have smokers not exposed.

It is a pleasure to ackowledge the cooperation of the Department of Health and Social Security, the Office of Population Censuses and Surveys, and the 
Cape Asbestos Company. We are grateful to Dr JC Wagner for checking the necropsy materal. The study was carried out with the help of a grant to MLN from the Medical Research Council.

\section{References}

' Berry G, Newhouse ML, Turok M. Combined effect of asbestos exposure and smoking on mortality from lung cancer in factory workers. Lancet 1972;ii:476-9.

2 Selikoff IJ, Hammond EC, Churg J. Asbestos exposure, smoking, and neoplasia. JAMA 1968;204:104-10.

${ }^{3}$ Case RA, Lea AJ. Mustard gas poisoning, chronic bronchitis, and lung cancer. Br J Prev Soc Med 1955;9:62-72.

${ }^{4}$ Doll R, Peto R. Mortality in relation to smoking: 20 years' observations on male doctors. Br Med J 1976;ii:1525-36.

s Doll R, Gray R, Hafner B, Peto R. Mortality in relation to smoking: 22 years' observations on female British doctors. Br Med J 1980;280:967-71.

- Todd GF. Statistics of smoking in the United Kingdom. 6th ed. London: Tobacco Research Council, 1969. (Research paper 1.)

' Berry G. The analysis of mortality by the subject-years method. Biometrics 1983;39:173-84.
${ }^{8}$ Baker RJ, Nelder JA. The GLIM system-release 3. Oxford: Numerical Algorithms Group, 1978.

${ }^{9}$ Saracci R. Asbestos and lung cancer: an analysis of the epidemiological evidence on the asbestos-smoking interaction. Int J Cancer 1977;20:323-31.

${ }^{10}$ Hammond EC, Selikoff IJ. Relation of cigarette smoking to risk of death of asbestos-associated disease among insulation workers in the United States. In: Bogovski P, Gilson JC, Timbrell V, Wagner JC, eds. Biological effects of asbestos. Lyon: International Agency for Research on Cancer 1973:312-7 (Scientific publications No 8.)

" Hammond EC, Selikoff IJ, Seidman H. Asbestos exposure, cigarette smoking and death rates. Ann NY Acad Sci 1979; 330: 473-90.

12 Selikoff IJ, Seidman H, Hammond EC. Mortality effects of cigarette smoking among amosite asbestos factory workers. J Natl Cancer Inst 1980;65:507-13.

${ }^{13}$ McDonald JC, Liddell FDK, Gibbs GW, Eyssen GE, McDonald AD. Dust exposure and mortality in chrysotile mining, 1910 75. Br J Ind Med"1980;37:11-24.

${ }^{14}$ Liddell FDK, Thomas DC, Gibbs GW, McDonald JC. Fibre exposure and mortality from pneumoconiosis, respiratory and abdominal malignancies in chrysotile production in Quebec, 1926-75. Third conference on epidemiology in occupational health, 1983, Singapore. (in press).

is McDonald AD, McDonald JC. Malignant mesothelioma in North America. Cancer 1980;46:1650-6.

${ }^{16}$ Selikoff IJ, Hammond EC. Asbestos and smoking. JAMA 1979; 242:458-9. 